\title{
Modern trends in base isolation applications for seismic protection of historic buildings
}

\author{
I. Iskhakov \& Y. Ribakov \\ College of Judea and Samaria, Ariel, Israel
}

\begin{abstract}
Historical buildings have relatively low height, are usually massive and their natural vibration period is rather low. Hence if such buildings are located in a seismically active region, using base isolation systems is a very effective way for improving their dynamic response. The idea of base isolation was known hundreds years ago, however practical implementation of modern base isolators started in the last few decades. The main advantage of a base isolation system is that no elements should be added to an isolated building, which is especially important for heritage architecture. A traditional base isolation system is obtained by using two main base isolator types - elastomeric (neoprene) bearings or friction pendulums. Hundreds of buildings all over the world are provided with such isolators and have proved enhanced dynamic behaviour. Design of base isolation systems and selection of their properties usually depend on dynamic characteristics of the isolated building. The latter can be obtained by non-destructive impulse testing of the structure before its protection. An appropriate method for structural dynamic parameters experimental estimation was developed by the authors. For this reason an impulse test was carried out on a three-story structural part of a building designed for a seismic region. In some cases the displacements at the base isolation level are rather big and exceed the allowed limits. In such cases it is recommended to add dampers to the base isolation system. Effective variable friction dampers were proposed and tested by the authors. These dampers significantly reduce the displacements at the isolator level (between the first floor column and foundation) and also yield further improvement in the seismic response of a building.
\end{abstract}

Keywords: historic buildings, base isolation, impulse tests, variable friction dampers, seismic response. 


\section{Introduction}

Base isolation is one of the significant developments in earthquake engineering in the past decades. It provides protection of building structural elements as well as non-structural components, which is important for heritage architecture. Normally, a building is supported on its foundations, and it has a fixed-base. When base isolation is used, special bearings are installed between the building and its foundation. The bearings are flexible in the horizontal direction and reduce the natural frequency of a building. As a result, the base isolated building's response to an earthquake is not so strong like of a fixed-base one.

The first application of a base isolation system was in New Zealand in 1974, in the US - in 1984 and in Japan - in 1985. Currently there are more than 80 base isolated buildings and 150 bridges in the US, 1000 buildings and 500 bridges in Japan and numerous applications in other countries. For example, in the USA almost $55 \%$ of government buildings and $45 \%$ private buildings are base isolated. Among them 12 historic buildings are retrofitted.

The most important advantage of using base isolation systems for seismic protection of historic buildings is that the retrofitting works are performed at the basement level. Sometimes there are certain technical and financial difficulties in applying the base isolators at the foundation level. However, addition of base isolation prevents any changes in the structural system and saves the historic value of the heritage architecture. An additional benefit of this solution is its relatively low cost compared to other ones.

The main idea of base isolation is "decoupling" the building from the ground motion. In this case transmission of seismic energy to the building is significantly reduced by increasing building's natural vibration period, allowing the building to displace with rather small inter-story drifts. It allows decreasing internal forces in the structural elements of the buildings during earthquakes. Classic base isolation systems are usually obtained by using two main base isolator types - elastomeric bearings (Figure 1) or friction pendulums (Figure 2).

As can be followed from Figure 1, an elastomeric bearing is a sandwich obtained by alternating layers of about $6 \mathrm{~mm}$ steel plate and $6 \mathrm{~mm}$ rubber which are vulcanized in order to form a single integrated unit. According to Figure 2, a friction pendulum consists of a concave plate, articulating slider and housing plate. Both types of isolators are able to displace horizontally in any direction from the centre depending on the seismic excitation's direction.

This paper is focused on review of using base isolation systems in historic buildings, non-destructive impulse testing for measuring structural dynamic parameters, using variable friction dampers for reducing displacements at the base isolator's level.

\section{Overview of base isolated historic buildings}

\subsection{Oakland City Hall}

The building was constructed in 1914 as the first high-rise government office in the United States and remains one of the country's finest examples of Beaux Arts 
architecture. The building suffered severe damage in the 1989 Loma Prieta earthquake and was immediately closed to occupancy. It is a beautiful building, with its three-story central rotunda, 10 -story base, and highly decorative clock tower. After the earthquake about $20 \%$ of the buildings lateral bearing capacity was lost in the north-south direction and about $30 \%$ in the east-west one. Extensive cracking of the structural elements appeared.

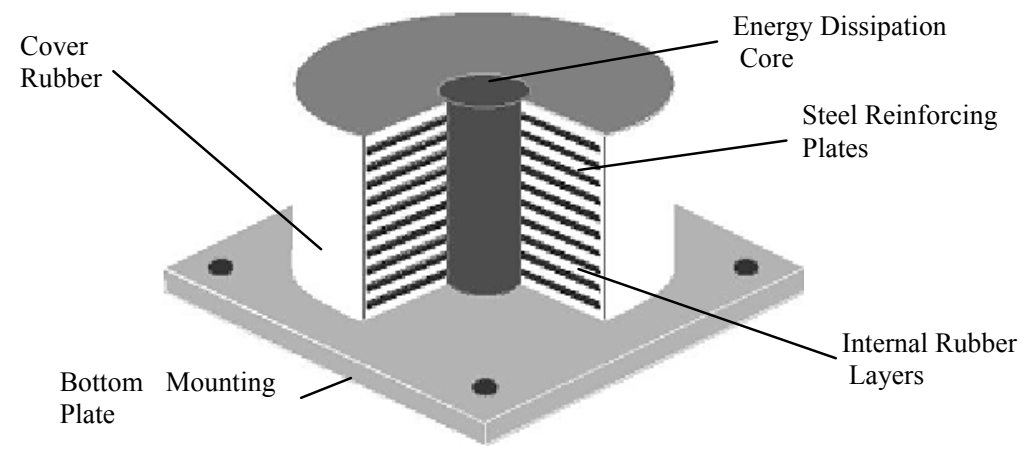

(a)

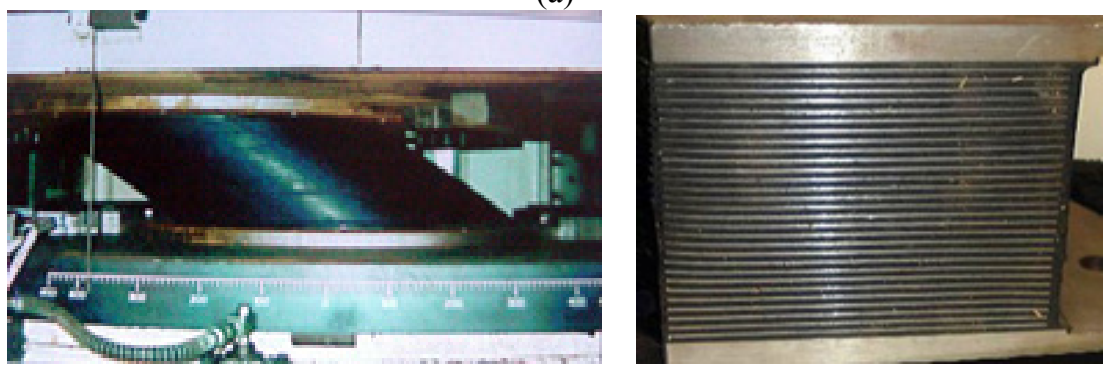

(b)

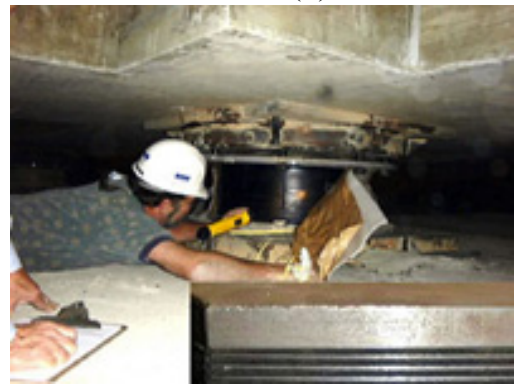

(d) (c)

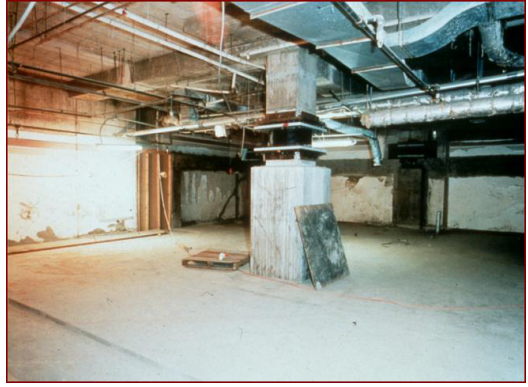

(e)

Figure 1: Elastomeric bearings: (a) principal scheme, (b) deformed stage, (c) general view, (d) installation process, (e) a column with a base isolator [1]. 


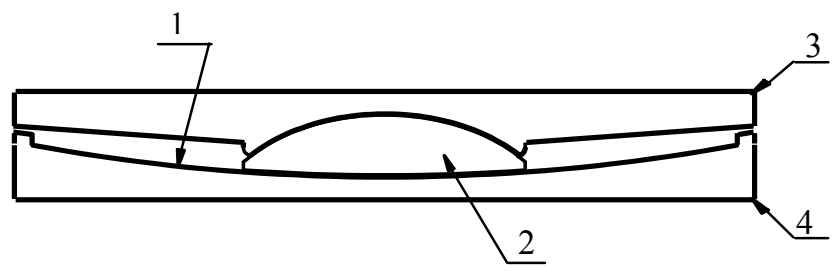

Figure 2: Friction pendulum principal scheme: 1- stainless steel concave surface, 2 - articulating slider, 3 - housing plate, 4 - concave plate.

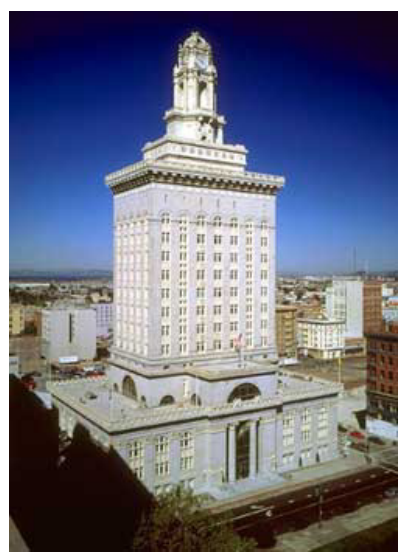

Figure 3: $\quad$ Base isolated Oakland City Hall.

It was decided to retrofit the structure using a base isolation system. The main aim was to restore the building to its majestic self and to increase its seismic resistance, so that future earthquakes would not cause similar damage. The building is now one of the tallest base-isolated structures in the world. It has a complete steel frame. The floors and roofs are made of reinforced concrete slabs supported on the frame. The foundation system is a reinforced concrete plate over the entire basement area. 112 isolators were installed in the basement.

\subsection{San Francisco City Hall}

The San Francisco's Old City Hall (Figure 4(a)) was constructed in the end of the XIX century. It was one of the finest examples of French Renaissance architecture in the country. During the 1906 earthquake the building was totally damaged, only the dome remained intact. It was finally rebuilt in 1915 (Figure 4(b)). During the 1989 Loma Prieta earthquake the City Hall was again subjected to strong seismic excitation. The dome twisted on its steel frame like a cap on a bottle, cracks in the walls and concrete floor slabs occurred at all levels [3]. The building was not in danger of collapse, but, according to experts' 


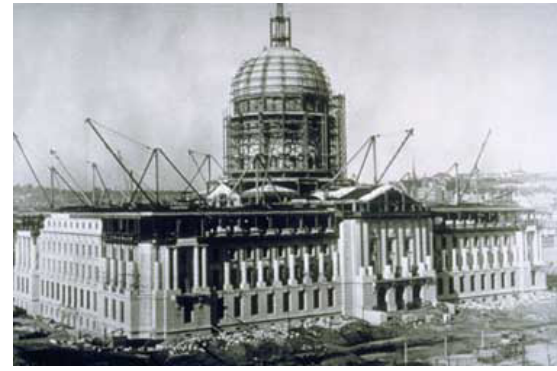

(a)

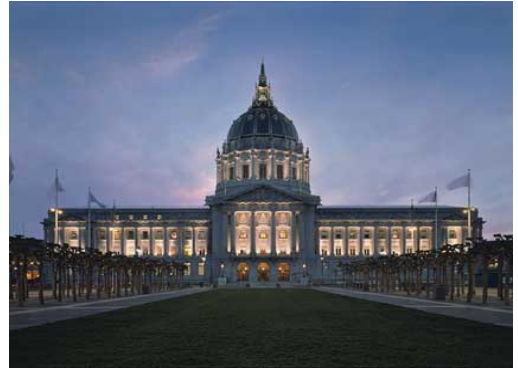

(b)

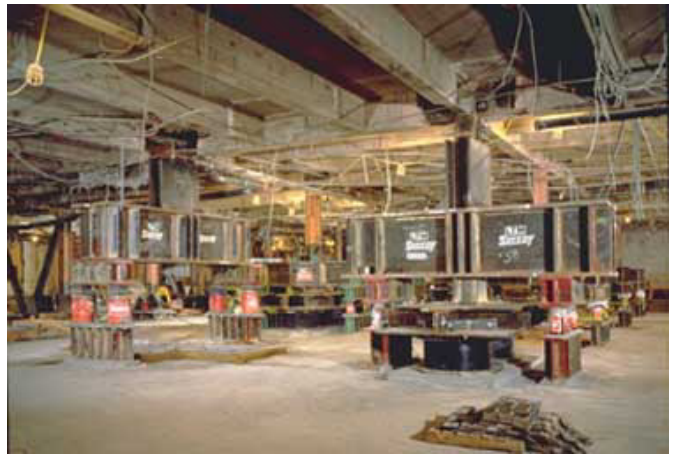

(c)

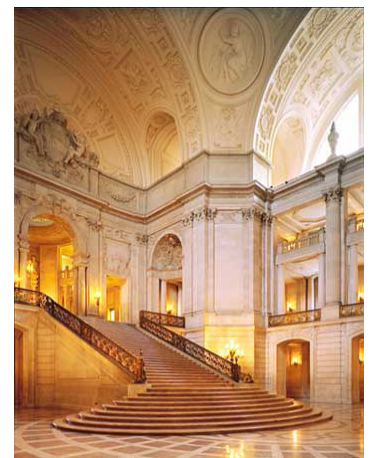

(d)

Figure 4: San Francisco City Hall: (a) before reconstruction, (b) modern view, (c) installing isolators under the columns, (d) entrance hall.

opinion, its seismic resistance was not enough to withstand the next big earthquake.

About ten years ago the building was isolated from its foundation and put on 530 bearings, which were designed to dissipate earthquake energy and allow the building to move horizontally up to $65 \mathrm{~cm}$ without shaking (Figure 4(c)). To install the isolators, the building columns were jacked up and cut, and the isolators were located between the columns and the foundation. Today, this structure is one of the finest examples of French Renaissance architecture and as one of the most seismically safe buildings.

\subsection{Base isolation of historic buildings in New Zealand}

One of New Zealand's most well known landmark buildings has undergone a complete seismic renovation [4]. The Parliament Buildings (Figure 5(a)) are originally built in the 1900s and located approximately 400 meters from one of the regions major fault lines. Over 400 base isolation elastomeric rubber bearings were installed between the structure and its foundation. The isolators allow the building to move horizontally about $40 \mathrm{~cm}$ in an earthquake. 
The Old Bank of New Zeeland (Figure 5(b)) was reconstructed and provided by base isolation system. This process involved tying together of four historic buildings to create an integrated retail and office development [4].

The Museum of New Zealand is home to some of New Zealand's national artefacts and has a rich knowledge of the countries past (Figure 5(c)). It is the largest in the Southern Hemisphere base isolated structure weighting about 64000 ton [4]. The base isolation system allows the building to move horizontally up to $50 \mathrm{~cm}$. The isolated building is designed to withstand an earthquake with a 7.5 Richter scale magnitude.

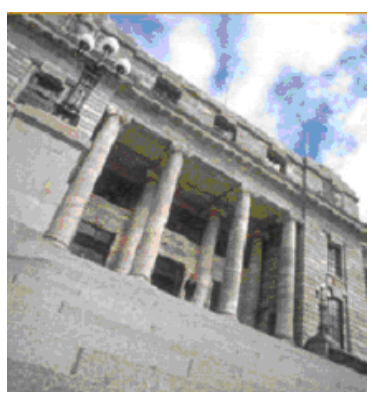

(a)

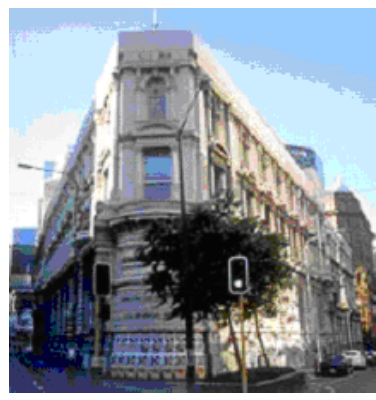

(b)

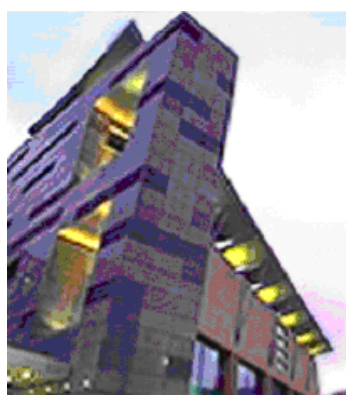

(c)

Figure 5: Base isolated structures in New Zeeland: (a) Parliament building, (b) Old bank in Wellington, (c) the Museum of New Zealand.

However, none of the heritage structures, retrofitted with base isolation systems, have been subjected yet to a strong earthquake, but other base isolated buildings proved enhanced behavior in this case (like the USC Hospital in California [8]).

\section{Overview of experimental methods for estimation of heritage buildings' dynamic parameters}

Selection of base isolation systems parameters directly depends on the structural dynamic characteristics. Known theoretical methods cannot be used for calculation of these characteristics because of the following reasons: the materials properties, elements masses, static schemes for old buildings and the hysteretic properties of their elements are not known exactly; it is difficult to take into account all the damages caused to the building during its operation.

One of widely known and often used methods is an impulse test (described below). It is effective for structural systems with concentrated masses. However, this is not the case for irregular structures or structures with distributed masses. Masonry and stone heritage buildings belong to these categories. In this case other methods for estimation of structural dynamic parameters should be applied.

One of such methods is a micro-seismic vibration due to a low power underground blast on a certain distance from the building. The blast load 
capacity and the distance from the structure in this case are calculated to avoid inelastic structural behaviour [5]. Another way to apply vibrations to the building is to put a vibration machine at the basement level. The parameters and the regime of the machine are regulated to cause only linear structural vibrations [6].

If the building is located in a region with high seismic activity, it is possible to provide it with seismometers working in a waiting regime. The seismometers may be tuned to be activated when even a low-magnitude earthquake will occur [6]. For framed heritage buildings with relatively low height and rather high flexibility impulse testing method developed by the authors [7] may be used.

\section{Impulse test procedure}

According to this method, the tests are carried out on a framed building. For example, tests, performed on a building part consisted of two columns (each three floors high) and three slabs were described in the previous work [7]. The columns were fixed in sockets in a $30-\mathrm{cm}$ thick raft foundation. Each of the slabs was constructed of two pre-cast over-column plates and a between-column plate $16 \mathrm{~cm}$ thick (Figure 6). The overall dimensions of the part were $3 \times 9 \mathrm{~m}$, the height of each story being $3 \mathrm{~m}$.

Dynamical impulse loads were applied to the column-slab joint at the roof level in the plane of the frame. The impulse was applied by instantaneous application of the load by means of a guy cable (Figure 7) which included a bar, made of high-strength steel. The forces were controlled by rupture of a steel bar and were equal to the required impulse load. Under the impulse load, the tested frame got free vibrations. A steel cable and a hook were installed across the top of the third-floor column. The cable included a wire for pulling the frame. One end of the wire was tied to the hook and the other end to a bulldozer, which tensioned the wire until its failure.

In order to obtain the dynamical parameters of the structure, two accelerometers were located horizontally in the plane of the investigated frame at each floor, and also on the ground. The accelerometers were calibrated and tuned using a laboratory shaking table prior to the start of the tests. The bars were also subjected to preliminary testing in the laboratory in order to measure their absolute deformation under the rupture forces. These measured deformations corresponded to the maximum displacements of the building's roof story under the impulse loads applied.

In order to obtain the dynamical parameters of the building, the acceleration records were analyzed using MATLAB software. The natural periods were determined by computation of a frequency response curve showing the resonant peak corresponding to each natural frequency of the structure [7]. From these data the real damping ratio of the first vibration mode was determined using a logarithmic decrement.

In the above described tests the bars section area was selected to vary the impulse forces applied to the structure. This approach may be also used in testing heritage buildings in order to avoid any damage to its elements. It should be 
630 Structural Studies, Repairs and Maintenance of Heritage Architecture X

noted that the impulse force magnitude should be enough to yield structural vibrations required to obtain the buildings dynamic parameters.
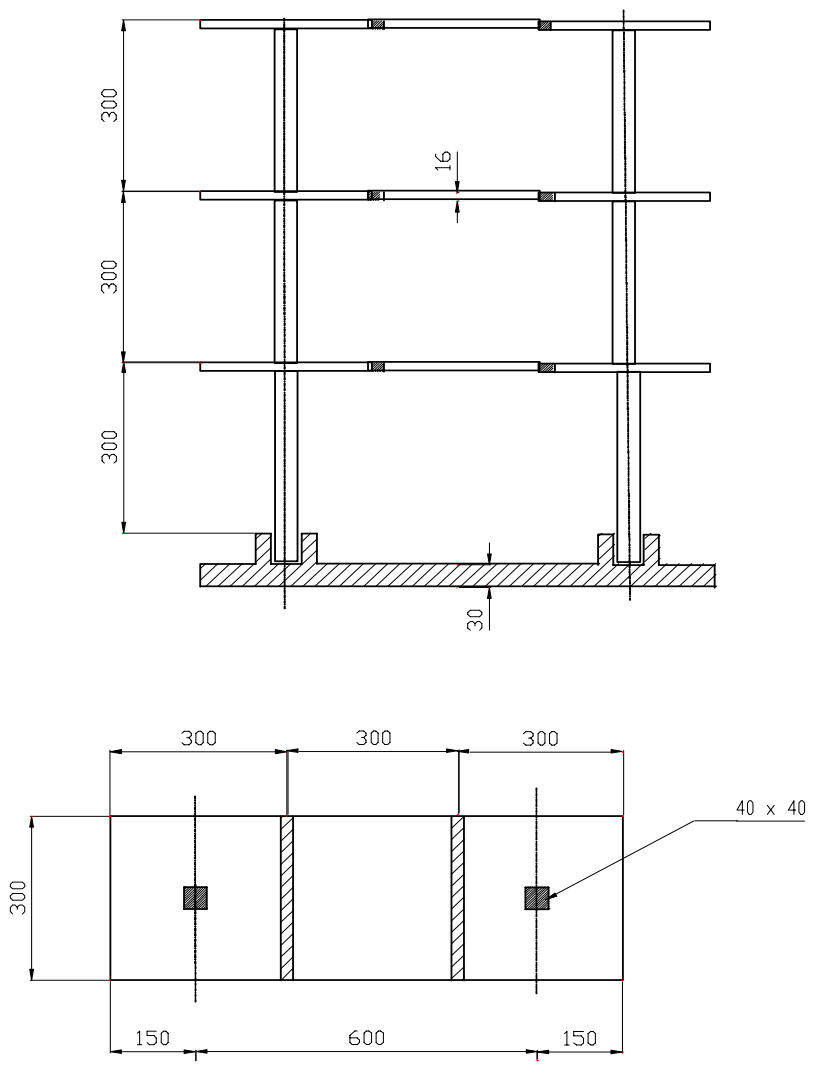

Figure 6: $\quad$ Structural scheme of tested part (following [7]).

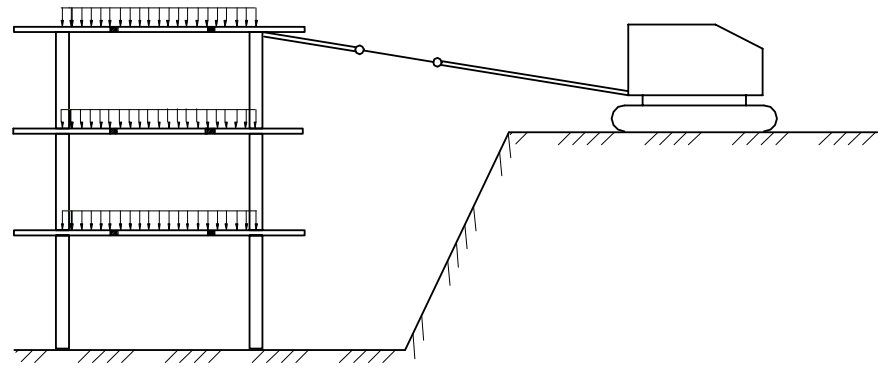

Figure 7: $\quad$ Application of impulse to building part (following [7]). 


\section{Using dampers in base isolation systems}

As it was mentioned above, base isolation systems significantly reduce interstory drifts, seismic forces and inelastic deformations in structural elements, preventing damages that may be caused to a building during an earthquake. Heritage architecture is especially sensitive to these influences. However, in some cases the influences are still unacceptable. Moreover, using base isolation systems yields relatively big displacements at the isolators' level, which is not always desired.

Addition of dampers to base isolation systems yields further improvement in structural response to earthquakes and decreases the displacements at the isolators [8]. Passive fluid viscous, friction and other types of dampers may successfully be used for this reason [9]. It is known that buildings with friction dampers don't return to the initial position after the earthquake. In order to overcome this drawback variable friction dampers were recently developed and tested by the authors $[10,11]$.

A variable friction damper (Figure 8) consists of a tube (1), a wedge (2), elastic strip elements (3) and a connection clip (4). The wedge may be linear or curved. It can move ahead and back along its axis. The strips are fixed on the tube by the connection clip, forming an elastic strip system. The stiffness of this system may be regulated by changing the location of the connection clip along the tube. The free ends of the cantilever strips have a contact with an inclined surface of the wedge.

The dampers mechanical properties and hysteretic behavior were studied theoretically and verified experimentally using laboratory models $[10,11]$. These dampers may be incorporated as a part of a base isolation system in order to yield enhanced structural response and to limit the displacements at the isolators.
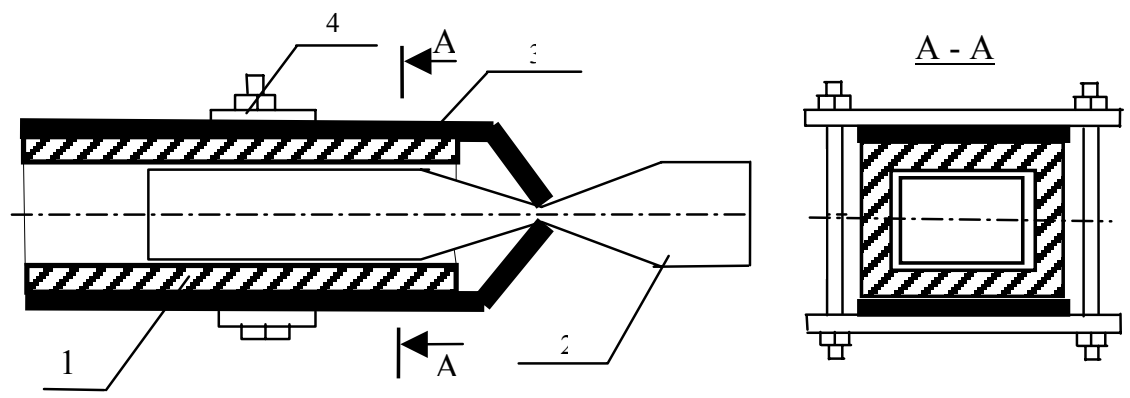

Figure 8: A principal scheme of the damper: 1 - square section tube; 2 -wedge; 3 - elastic strip elements; 4 - bolted connection clip (following [10]).

\section{Conclusions}

Base isolation has significant benefits for the earthquake protection of historic structures. It provides high protection level after a strong earthquake by reducing 
the buildings' seismic response. Thus, base isolation is an acceptable and an effective way for protection of historic buildings in areas of high seismic activity.

Recent earthquakes have shown that base isolated historic buildings retrofitted to withstand earthquakes behaved better compared to fixed-base ones. The main advantage of a base isolation system is that no elements should be added to an isolated building, which is especially important for heritage architecture.

Design of base isolation systems and selection of their properties usually depend on dynamic characteristics of the isolated building. The last can be obtained by non-destructive impulse testing of the structure before its protection.

Rather big displacements at the isolators' level can be reduced by adding supplemental dampers to the base isolation system. Effective variable friction dampers were proposed and tested by the authors. These dampers significantly reduce the displacements between the first floor column and foundation and also yield further improvement in the seismic response of a building.

\section{References}

[1] Los Angeles City Hall seismic rehabilitation project, Internet resource http://www.lacityhall.org/isohow.html

[2] Zayas, V. Friction pendulum seismic isolation bearings, Internet resource http://www.cif.org/Nom2000/Nom08_00.PDF

[3] San Francisco City Hall, Internet resource http://www.celebratingeqsafety.com/sf-city-hall

[4] Holmes Consulting Group - Base Isolation, Internet resource http://www.holmesgroup.com/baseisolation.html

[5] Negmatulaev, S.H., Djabarov. M.D. and Sirma, O.V., Full-scale dynamic tests of clay brick buildings using seismic-blast method, Proc. of the Int. Conf. on Modern Aspects in Development of Seismic Resistance and Seismology: Dushanbe, pp. 172-178, 2005 (in Russian).

[6] Iskhakov, I., Calculation and Design of RC Shells for Seismic Regions, Maorif, Dushanbe, 1983 (in Russian).

[7] Iskhakov, I. \& Ribakov, Y., Selecting the properties of a base isolation system based on impulse testing of a three-story structural part. European Earthquake Engineering, XIX (1), pp. 38-42, 2005.

[8] Naeim, F. \& Kelly, J., Design of seismic isolated structures: from theory to practice, Wiley, NY, 1999.

[9] Chang, S., Makris, N., Whittaker, A. \& Thompson, A. Experimental and analytical studies on the performance of hybrid isolation systems. Earthquake Engineering and Structural Dynamics, 31, pp. 421-443, 2002.

[10] Ribakov, Y., Blostotsky, B. \& Iskhakov, I., Theoretical model and laboratory tests of variable friction damper, European Earthquake Engineering, 1, pp. 36 - 42, 2006.

[11] Ribakov, Y., Blostotsky, B. \& Iskhakov, I., An efficient variable friction damper with a curved wedge, European Earthquake Engineering, 2, pp. 32-38, 2006. 